\title{
Astaxanthin inhibits homocysteine-induced endothelial cell dysfunction via the regulation of the reactive oxygen species-dependent VEGF-VEGFR2-FAK signaling pathway
}

\author{
XIAN-JUN WANG $^{1 *}$, DA-CHEN TIAN ${ }^{1 *}$, FENG-WEN WANG $^{2}$, MENG-HAO ZHANG $^{2}$, \\ CUN-DONG FAN ${ }^{2}$, WANG CHEN ${ }^{1}$, MEI-HONG WANG ${ }^{1}$, XIAO-YAN FU ${ }^{2}$ and JIN-KUI MA ${ }^{3}$ \\ ${ }^{1}$ Department of Neurology, People's Hospital of Linyi Affiliated to Qingdao University, Linyi, \\ Shandong 276000; ${ }^{2}$ Department of Biochemistry, Basic Medical School, Taishan Medical University, \\ Taian, Shandong 271000; ${ }^{3}$ Department of Food Science and Technology, School of Food and \\ Pharmaceutical Engineering, Zhaoqing University, Zhaoqing, Guangdong 526061, P.R. China
}

Received September 5, 2018; Accepted April 10, 2019

DOI: $10.3892 / \mathrm{mmr} .2019 .10162$

\begin{abstract}
Increased plasma levels of homocysteine (Hcy) can cause severe damage to vascular endothelial cells. Hcy-induced endothelial cell dysfunction contributes to the occurrence and development of human cerebrovascular diseases (CVDs). Our previous studies have revealed that astaxanthin (ATX) exhibits novel cardioprotective activity against Hcy-induced cardiotoxicity in vitro and in vivo. However, the protective effect and mechanism of ATX against Hcy-induced endothelial cell dysfunction requires further investigation. In the present study, treatment of human umbilical vascular endothelial cells (HUVECs) with Hcy inhibited the migration, invasive and tube formation potentials of these cells in a dose-dependent manner. Hcy treatment further induced a time-dependent increase in the production of reactive oxygen species (ROS), and downregulated the expression of vascular endothelial growth factor (VEGF), phosphorylated (p)-Tyr-VEGF receptor 2 (VEGFR2) and p-Tyr397-focal adhesion kinase (FAK). On the contrary, ATX pre-treatment significantly inhibited Hcy-induced cytotoxicity and increased HUVEC migration, invasion and tube formation following Hcy treatment. The mechanism of action may involve the effective inhibition of Hcy-induced ROS generation and the recovery of FAK phosphorylation. Collectively, our findings suggested that ATX could inhibit Hcy-induced endothelial dysfunction by suppressing
\end{abstract}

Correspondence to: Dr Jin-Kui Ma, Department of Food Science and Technology, School of Food and Pharmaceutical Engineering, Zhaoqing University, Zhaoqing Avenue, Zhaoqing, Guangdong 526061, P.R. China

E-mail: jinkuima@gmail.com

*Contributed equally

Key words: homocysteine, astaxanthin, endothelial dysfunction, cerebrovascular diseases, focal adhesion kinase phosphorylation
Hcy-induced activation of the VEGF-VEGFR2-FAK signaling axis, which indicates the novel therapeutic potential of ATX in treating Hcy-mediated CVD.

\section{Introduction}

Endothelial dysfunction has been identified as one of the most important pathogenetic causes of human cerebrovascular disease (CVD) $(1,2)$. Endothelial dysfunction can cause damage to the blood-brain barrier and can result in a range of neurological disorders, including multiple sclerosis, vascular dementia and subsequent complications of the extremities (3-5). Cerebral small vessel disease is a condition that involves the formation of white matter lesions and cerebral microbleeds, and has been associated with endothelial dysfunction (6).

Elevated serum levels of homocysteine (Hcy) is an independent risk factor that can damage vascular endothelial cells and can cause endothelial dysfunction, which in turn contributes to the occurrence and development of CVDs (7-9). Several studies have focused on the ability of Hcy to lower the severity of numerous human diseases (10-12). Hcy-induced apoptosis of endothelial cells has been reported to account for Hcy-dependent vascular injury (13). Accumulated evidence suggests that Hcy can cause endothelial dysfunction. For example, Hcy can inhibit endothelial nitric oxide (NO) synthase signaling (14) and cell migration by targeting key angiogenic factors (15). Furthermore, it can reduce the expression levels of vascular endothelial growth factor (VEGF)-A and vascular endothelial growth factor receptor (VEGFR)-2 (16,17). Hcy can inhibit microvascular endothelial cell formation by disrupting cell migration via an inducible NO synthase-dependent mechanism $(18,19)$. Hcy can decrease the invasive potential of endothelial cells by inhibiting matrix metalloproteinase (MMP)-2 and urokinase (19); however, the mechanism of cytotoxicity of Hcy on endothelial cells remains unclear. Furthermore, to the best of our knowledge, the role of reactive oxygen species (ROS) in endothelial dysfunction has not been investigated previously. 
Astaxanthin (ATX) is a potent antioxidant that undertakes a novel mechanism of action. Our previous study revealed that ATX can attenuate Hcy-induced cardiotoxicity in vitro and in vivo by inhibiting mitochondrial dysfunction and oxidative damage (20). It was reported that ATX could attenuate the astrocyte apoptosis and reduce traumatic brain injury by inhibiting $\mathrm{Na}-\mathrm{K}-\mathrm{Cl}$ co-transporter (NKCC1) and the secretion of proinflammatory cytokines (21). These effects were caused by the suppression of oxidative stress and the upregulation of brain-derived neurotrophic factor and nerve growth factor mRNA $(22,23)$. ATX exerted neuroprotective effects against subarachnoid hemorrhage damage that involved the inhibition of MMP-9 expression, the upregulation of Akt/glycogen synthase kinase- $3 \beta$ and the activation of the nuclear factor-like 2-antioxidant responsive element pathway (24-32); however, the protective effects of ATX against Hcy-induced endothelial dysfunction and the underlying mechanism require further investigation.

\section{Materials and methods}

Materials. Dulbecco's Modified Eagles medium (DMEM)/ F-12 and fetal bovine serum (FBS) were purchased from Gibco (Thermo Fisher Scientific, Inc.). ATX (purity, 97\%), Hcy (purity, 98\%), MTT and propidium iodide were obtained from Sigma-Aldrich (Merck KGaA). All primary antibodies used in the present study, including anti-VEGF (cat. no. 2463), VEGFR2 (cat. no. 9698), phosphorylated (p)-VEGFR2 (cat. no. 2478), Tyr397-focal adhesion kinase (FAK; cat. no. 3283), FAK (cat. no. 3285) and $\beta$-actin (cat. no. 8457) were purchased from Cell Signaling Technology, Inc. A horseradish peroxidase-linked goat anti-rabbit immunoglobulin $\mathrm{G}$ (cat. no. 7074; Cell Signaling Technology, Inc.) was used as the secondary antibody. PF-562271 was purchased from Selleck Chemicals. All solvents used were of high-performance liquid chromatography grade.

Cell viability assay. Human umbilical vein endothelial cells (HUVECs) were obtained from the American Type Culture Collection. HUVECs were cultured in DMEM-F12 containing $10 \% \mathrm{FBS}$ at $5 \% \mathrm{CO}_{2}$ and $37^{\circ} \mathrm{C}$ in an incubator. Cells $\left(8 \times 10^{3}\right.$ cells/well $)$ were seeded in a 96 -well plate and treated with Hcy $(1,2,5,10$ and $20 \mathrm{mM})$ at $37^{\circ} \mathrm{C}$ for $72 \mathrm{~h}$. In addition, cells were pre-treated with $1,2,5$ and $10 \mu \mathrm{M}$ ATX at $37^{\circ} \mathrm{C}$ for $6 \mathrm{~h}$ and then incubated with $10 \mathrm{mM}$ Hcy at $37^{\circ} \mathrm{C}$ for $72 \mathrm{~h}$. Following treatment, $20 \mu 1 \mathrm{MTT}$ solution was added and the cells were incubated at $37^{\circ} \mathrm{C}$ for another $5 \mathrm{~h}$. Subsequently, the medium was removed and $150 \mu \mathrm{l}$ of dimethyl sulfoxide was added. Cell viability was analyzed at room temperature $\left(25^{\circ} \mathrm{C}\right)$ by detecting the absorbance at $570 \mathrm{~nm}$. The morphology of HUVECs was observed under a phase contrast-microscope (magnification, $\mathrm{x} 400$; Nikon Corporation). Five randomly-selected fields of view per sample were imaged.

Cell migration assay. HUVEC migration was measured by a wound-healing migration assay. Briefly, HUVECs were seeded in a 6-well tissue culture plate and cultured at $37^{\circ} \mathrm{C}$ for $24 \mathrm{~h}$. Scratched wounds were created by scraping the cell monolayer with a sterile $10 \mu \mathrm{l}$ pipette tip. Subsequently, the cells were cultured with DMEM/F-12 medium (containing $1 \%$ FBS). Subsequently, the cells were pre-treated with $5 \mu \mathrm{M}$ ATX for $6 \mathrm{~h}$ and/or $10 \mathrm{mM} \mathrm{Hcy}$ or $10 \mathrm{nM}$ PF562271 at $37^{\circ} \mathrm{C}$ for $48 \mathrm{~h}$. Untreated cells were used as control. The migrated cells were imaged in five randomly-selected fields of view with a phase-contrast microscope (magnification, x200) and the percentage of migration was quantified by manual counting (\% of control).

Cell invasion assay. HUVECs were pre-treated with $5 \mu \mathrm{M}$ ATX for $6 \mathrm{~h}$ and/or co-incubated with $10 \mathrm{mM} \mathrm{Hcy}$ at $37^{\circ} \mathrm{C}$ for $72 \mathrm{~h}$. Following treatment, HUVECs $\left(4 \times 10^{4}\right.$ cells/well $)$ were suspended in $100 \mu 1 \mathrm{DMEM} / \mathrm{F}-12$ medium (FBS-free) and were seeded in the upper layer of a Matrigel pre-coated Transwell chamber. Complete DMEM/F12 (600 $\mu 1,10 \%$ FBS) was added into the lower chamber. Following a $24 \mathrm{~h}$ incubation period at $37^{\circ} \mathrm{C}$, the non-invaded cells on the Transwell were removed using a cotton swab; invaded cells were washed with PBS, fixed with $10 \%$ ethanol for $10 \mathrm{~min}$ at room temperature $\left(25^{\circ} \mathrm{C}\right)$ and stained with $0.1 \%$ crystal violet for $15 \mathrm{~min}$ at room temperature $\left(25^{\circ} \mathrm{C}\right)$. Invaded cells were measured by manual counting with a Nikon Ti-S inverted microscope (magnification, $\mathrm{x} 200$ ). In total, five randomly-selected fields of view per sample were imaged and analyzed.

Tube formation. In vitro tube formation was examined by a Transwell assay. Briefly, HUVECs were pre-treated with $5 \mu \mathrm{M}$ ATX for $6 \mathrm{~h}$ and/or co-incubated with $10 \mathrm{mM}$ Hcy at $37^{\circ} \mathrm{C}$ for $72 \mathrm{~h}$. Following treatment, HUVECs $\left(10^{4}\right.$ cells/well $)$ were seeded in Matrigel pre-coated 48-well plates and incubated at $37^{\circ} \mathrm{C}$ for $24 \mathrm{~h}$. In total, five randomly-selected fields of view per sample were imaged, and the number of tubes formed manually counted using a Nikon inverted microscope (magnification, $\mathrm{x} 100$ ).

ROS measurement. The levels of intracellular ROS in HUVECs were detected by the 2'7'-dichlorfluorescein diacetate (DCFH-DA). Briefly, HUVECs were incubated with $10 \mu \mathrm{M}$ DCFH-DA for $20 \mathrm{~min}$ at $37^{\circ} \mathrm{C}$ in the dark. Subsequently, the cells were washed with PBS and treated with $10 \mathrm{mM} \mathrm{Hcy}$ at $37^{\circ} \mathrm{C}$ for $10,30,60$ and $120 \mathrm{~min}$. On the contrary, cells were treated with $5 \mu \mathrm{M}$ ATX for $60 \mathrm{~min}$ and/or co-treated with $10 \mathrm{mM} \mathrm{Hcy}$ at $37^{\circ} \mathrm{C}$ for $120 \mathrm{~min}$ to analyze the protective effects of ATX. For ROS inhibition, cells were pre-treated with $5 \mathrm{mM}$ glutathione (GSH) at $37^{\circ} \mathrm{C}$ for $2 \mathrm{~h}$ prior to ATX/Hcy treatment. The production of ROS was quantified using a microplate reader by measuring the fluorescence intensity at an excitation wavelength of $488 \mathrm{~nm}$ and an emission wavelength of $525 \mathrm{~nm}$.

Western blotting. Protein expression was detected by western blotting. Briefly, HUVECs were pre-treated with $5 \mu \mathrm{M}$ of ATX for $6 \mathrm{~h}$ and/or co-incubated with $10 \mathrm{mM} \mathrm{Hcy}$ at $37^{\circ} \mathrm{C}$ for $72 \mathrm{~h}$. Following treatment, the cells were collected and lysed on ice for $1 \mathrm{~h}$ at $4^{\circ} \mathrm{C}$ in RIPA lysis buffer (Nanjing KeyGen Biotech Co., Ltd.). Total protein was quantified with a Bicinchoninic Acid detection kit. A total of $40 \mu \mathrm{g}$ of protein was added and separated on a $10 \%$ SDS gel at $110 \mathrm{~V}$ for $75 \mathrm{~min}$. Following electrophoresis, the proteins were transferred from the gel onto the nitrocellulose membrane. The membrane was blocked 
A

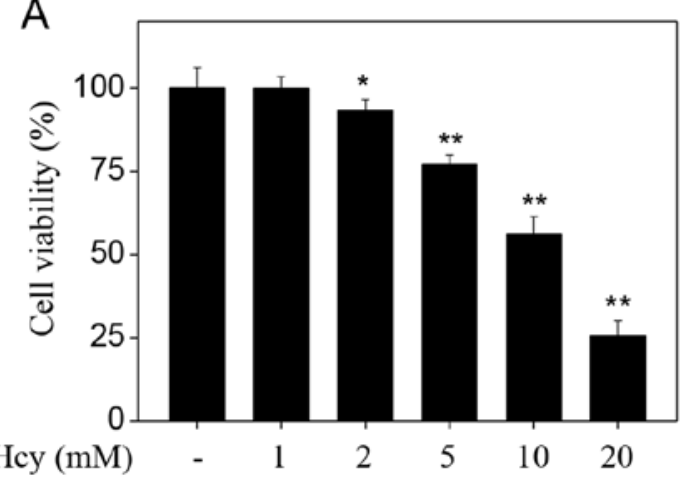

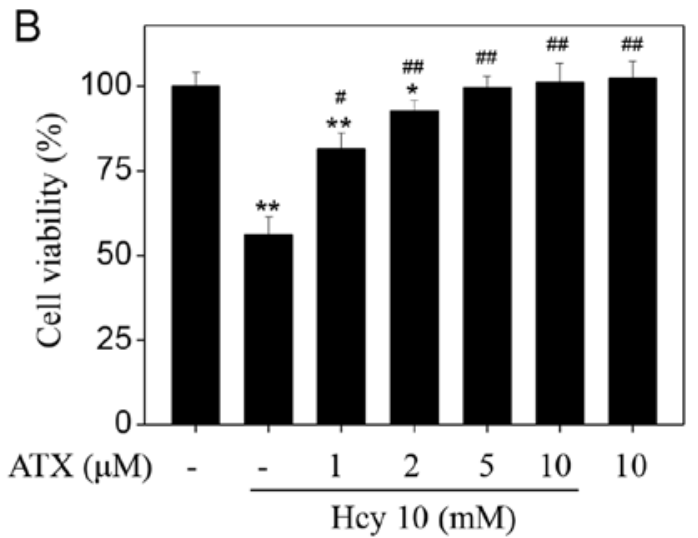

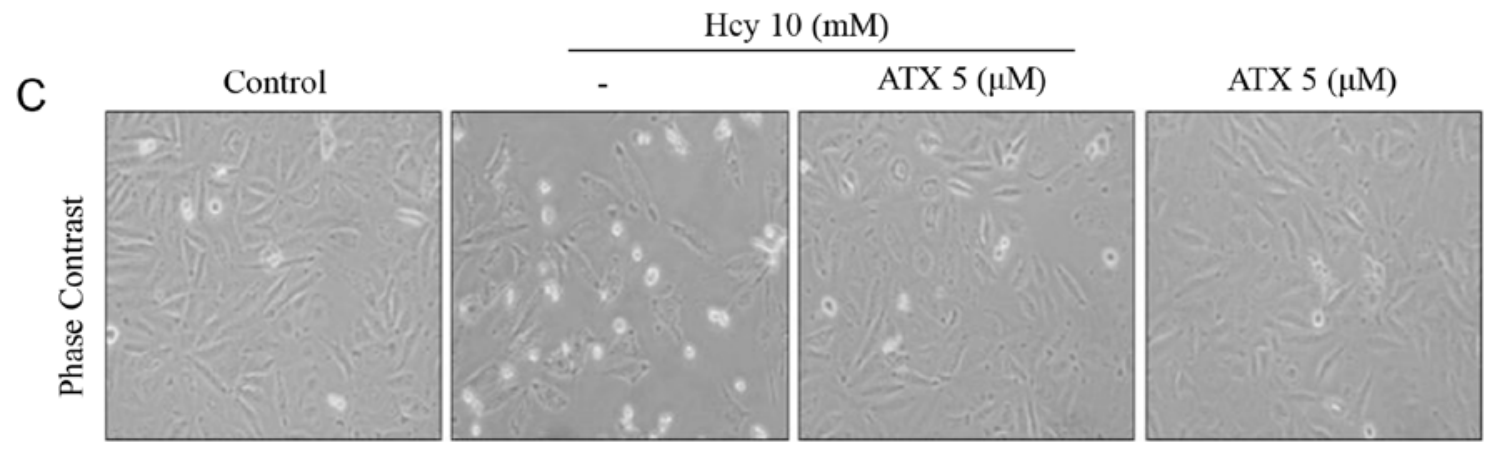

Figure 1. ATX inhibits Hcy-induced cytotoxicity in HUVECs. (A) Cytotoxicity of Hcy towards HUVECs. Cells (8,000 cells/well) were seeded in 96-well plate and treated with Hcy for $72 \mathrm{~h}$. (B) ATX pre-treatment inhibited Hcy-induced HUVEC cytotoxicity. Cells were pretreated with 1-10 $\mu \mathrm{M}$ ATX for $6 \mathrm{~h}$ and co-treated with $10 \mathrm{mM}$ Hcy for $72 \mathrm{~h}$. Cell viability was detected by an MTT assay. (C) Morphological changes of HUVECs. Following treatment, cells were observed under a phase-contrast microscope (magnification, $\mathrm{x} 400$ ). All data and images were obtained from three independent experiments. ${ }^{*} \mathrm{P}<0.05$, ${ }^{* *} \mathrm{P}<0.01$ vs. control; ${ }^{\#} \mathrm{P}<0.05,{ }^{\# \#} \mathrm{P}<0.01$ vs. Hcy-treated group. ATX, astaxanthin; Hcy, homocysteine; HUVECs, human umbilical vascular endothelial cells.

with $5 \%$ non-fat milk at room temperature $\left(25^{\circ} \mathrm{C}\right)$ for $1 \mathrm{~h}$ and incubated overnight with a primary antibody $(1: 1,000)$ at $4^{\circ} \mathrm{C}$, followed by incubation with the secondary antibody $(1: 2,000)$ for $1 \mathrm{~h}$ at room temperature $\left(25^{\circ} \mathrm{C}\right)$. The target protein was scanned with $\mathrm{X}$-ray film using an enhanced chemiluminescence system (Kodak). $\beta$-actin was used as the reference protein.

Statistical analysis. The experiments were repeated three times. Statistical analysis was conducted with the SPSS software (version 13.0; SPSS, Inc.). Data are presented as the mean \pm SD. Statistical evaluation was analyzed by one-way ANOVA followed by a Dunnett's or Tukey's post-hoc test. $\mathrm{P}<0.05$ was considered to indicate a statistically significant difference.

\section{Results}

ATX inhibits Hcy-induced cytotoxicity in HUVECs. Initially, the toxicity of Hcy towards HUVECs was examined by an MTT assay. Hcy alone apparently suppressed HUVEC viability in a dose-dependent manner (Fig. 1A). Treatment of HUVECs with 5, 10 and $20 \mathrm{mM}$ Hcy significantly suppressed the cell viability from $100 \%$ (control) to $77.1,56.2$ and $25.5 \%$, respectively. On the contrary, pre-treatment of HUVECs with ATX could restore the cell viability inhibited by Hcy. Pre-treatment of HUVECs with 1, 2 and $5 \mu \mathrm{M}$ ATX significantly increased cell viability from $56.2 \%$ (Hcy, $10 \mathrm{mM}$ ) to $86.1,92.7$ and
99.6\%, respectively (Fig. 1B). ATX $(10 \mu \mathrm{M})$ alone indicated no cytotoxicity towards HUVECs. In addition, ATX pre-treatment ameliorated morphological changes induced by Hcy in HUVECs. Hcy treatment notably decreased cell number, and induced cell shrinkage (Fig. 1C). These results suggested that ATX could inhibit Hcy-induced cytotoxicity in HUVECs.

ATX increases cell migration, invasion and tube formation in Hcy-treated HUVECs. To examine the effects on the functions of endothelial cells, we examined HUVEC migration, invasion and tube formation, which are considered indices of angiogenesis. Initially, Hcy-treated HUVEC migration was analyzed by a wound-healing assay. Hcy treatment alone significantly inhibited the migration of HUVECs compared with untreated cells (Fig. 2A), which was demonstrated by the distance between the edges of the wounded region following $48 \mathrm{~h}$. On the contrary, ATX pre-treatment appeared to improve the migration of Hcy-treated cells. Hcy treatment $(10 \mathrm{mM})$ significantly inhibited the migration rate from $100 \%$ (control) to $17.9 \%$; however, ATX pre-treatment $(5 \mu \mathrm{M})$ significantly improved the migration rate to $77.8 \%$ (Fig. 2B). ATX treatment alone indicated no significant effect on HUVEC migration compared with untreated cells. The potency of ATX was further examined using cell invasion and tube formation assays. Hcy treatment alone $(10 \mathrm{mM})$ significantly inhibited cell invasion and tube formation compared with the untreated control, whereas ATX pre-treatment $(5 \mu \mathrm{M})$ significantly improved cell invasion and tube formation in Hcy-treated cells 

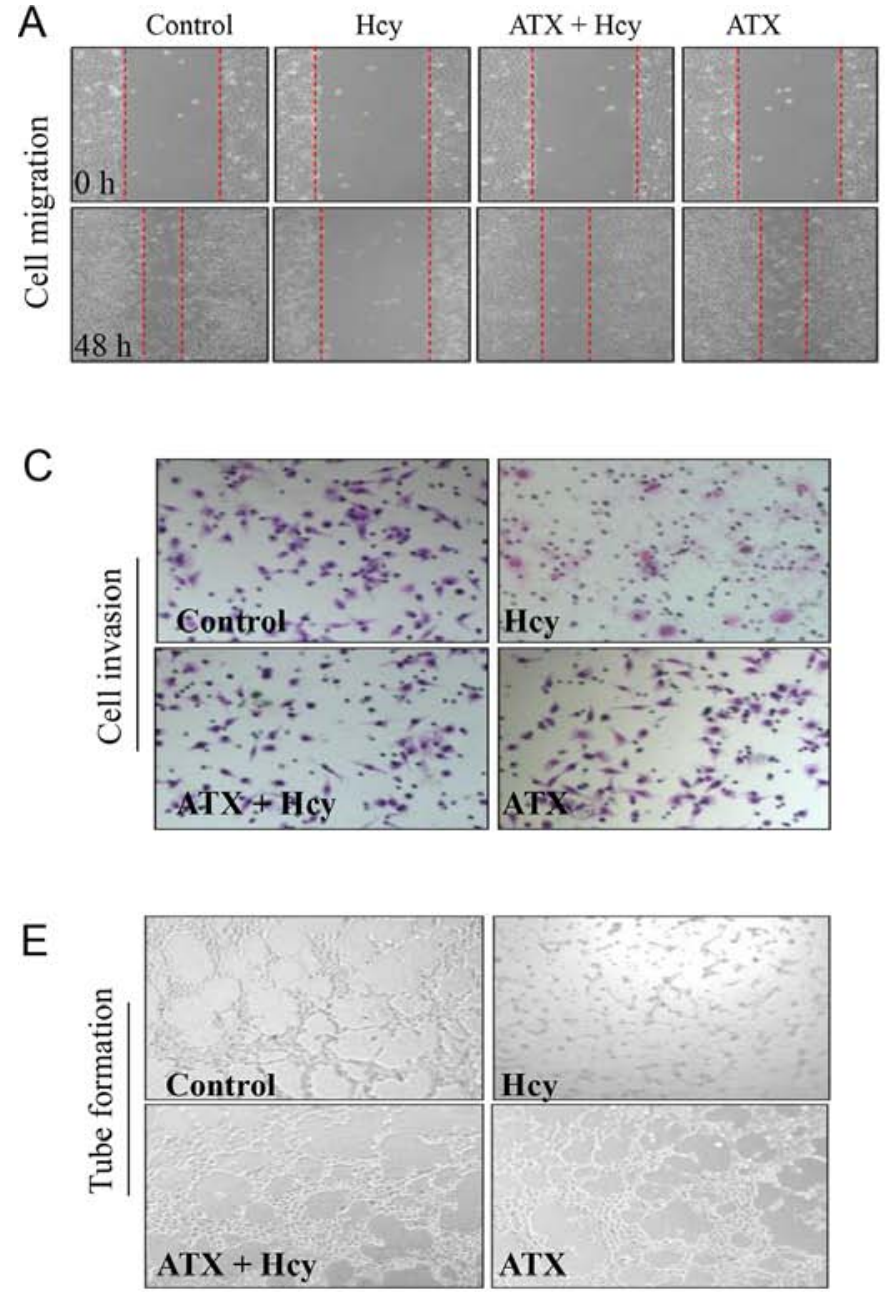
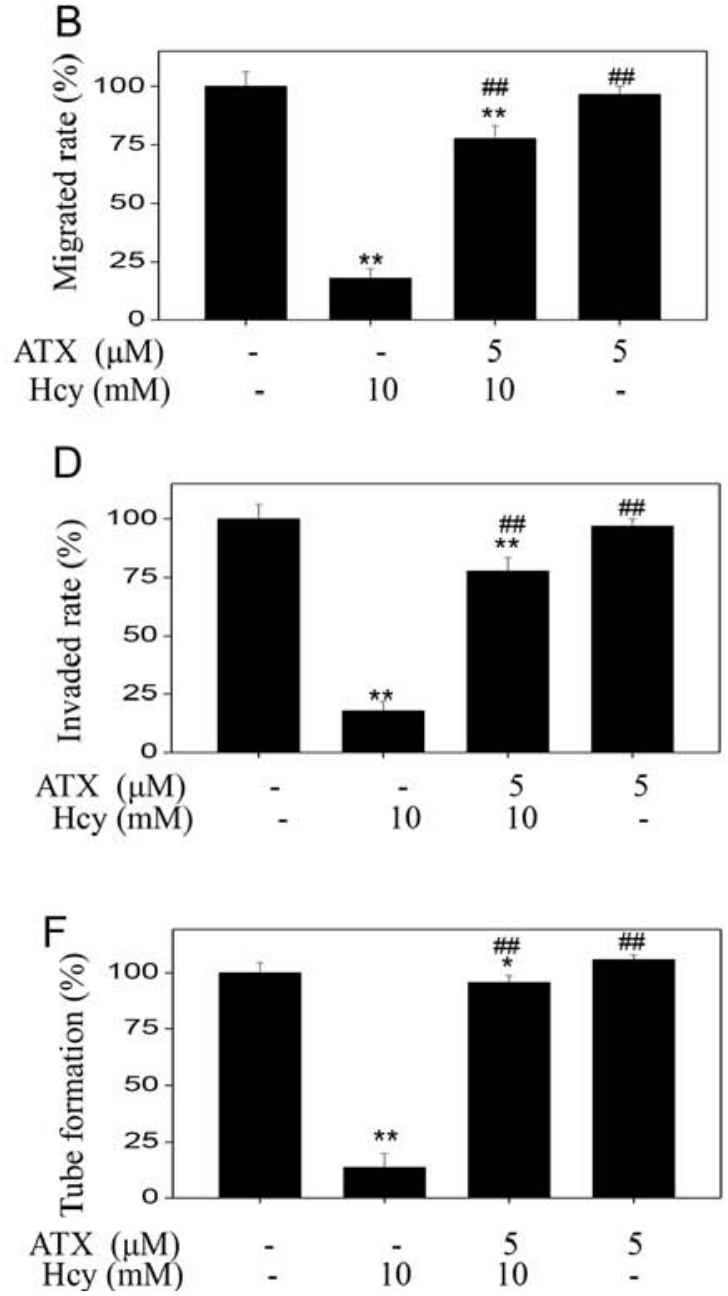

Figure 2. ATX improves cell migration, invasion and tube formation in Hcy-treated HUVECs. (A) ATX improved HUVECs migration. Cells were seeded in a 6-well plate and cultured until confluent. Cells were scraped by with a pipette tip and treated with ATX for $6 \mathrm{~h}$ or/and co-treated with Hcy $48 \mathrm{~h}$ (magnification, x100). (B) Statistical analysis of the rate of migration. (C) ATX improved HUVEC invasion. The invasive potential of cells was analyzed by a Transwell assay (magnification, x200). (D) Statistical analysis of the rate of invasion. (E) ATX improved HUVEC tube formation. (F) Statistical analysis of tube formation. The migrated cells, invaded cells and the number of tubes formed were all calculated by manual counting, and expressed as a percentage of the control (magnification, $\mathrm{x} 200$ ). All data and images were obtained from three independent experiments. ${ }^{*} \mathrm{P}<0.05,{ }^{* *} \mathrm{P}<0.01 \mathrm{vs}$. control; ${ }^{\# \#} \mathrm{P}<0.01 \mathrm{vs}$. Hcy-treated group. ATX, astaxanthin; Hcy, homocysteine; HUVECs, human umbilical vascular endothelial cells.

(Fig. 2C-F). Collectively, these results indicated that ATX could improve cell migration, invasion and tube formation in Hcy-treated HUVECs.

ATX inhibits Hcy-induced effects on the VEGF-VEGFR2-FAK signaling pathway. Accumulating evidence has suggested that the VEGF-VEGFR2-FAK is one of the most important pro-angiogenenic signaling pathways that serve a key role in regulating cell migration, invasion and tube formation (33). This pathway can be potentially targeted for therapeutic intervention. Therefore, in the present study, the expression levels of proteins involved in the VEGF-VEGFR2-FAK pathway were detected by western blotting. Treatment of cells with Hcy induced a significant time-dependent decrease in the expression of VEGF, p-Tyr-VEGFR2 and p-Tyr397-FAK (Fig. 3A). Notable changes were noted in the expression levels of total-FAK and total-VEGFR2 in Hcy-treated cells. To further evaluate the role of FAK, we used the FAK inhibitor, PF562271. The results indicated that treatment with PF562271 markedly enhanced the Hcy-induced inhibition of
p-Tyr397-FAK expression (Fig. 3B). Additionally, PF562271 and Hcy significantly inhibited of HUVEC migration compared with the control (Fig. 3D), which suggested that Hcy inhibited HUVEC migration in a FAK-dependent manner. However, ATX pre-treatment markedly recovered the expression of p-Tyr397-FAK in HUVECs that were induced by the combined treatment of the FAK inhibitor and Hcy (PF562271+ Hcy). ATX pre-treatment $(5 \mu \mathrm{M})$ reversed the effects of combined treatment of PF562271 and Hcy on FAK phosphorylation (Fig. 3C). In addition, ATX pre-treatment significantly increased the rate of migration of HUVECs (47.8\%) compared with the combined treatment $(8.99 \%$; Fig. $3 \mathrm{E})$. Collectively, these findings indicated that ATX could inhibit Hcy-induced dysfunction of the VEGF-VEGFR2-FAK signaling pathway.

ATX inhibits ROS-dependent FAK phosphorylation. Accumulating evidence has shown that Hcy can induce ROS accumulation, which can further cause cytotoxicity (20-22). Therefore, the intracellular accumulation of ROS in Hcy-treated HUVECs was examined. Hcy treatment induced 
A

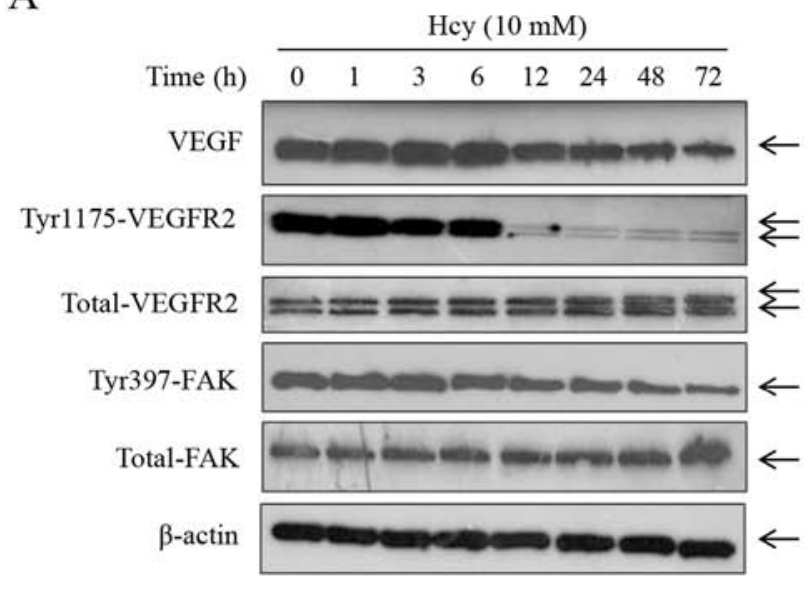

D

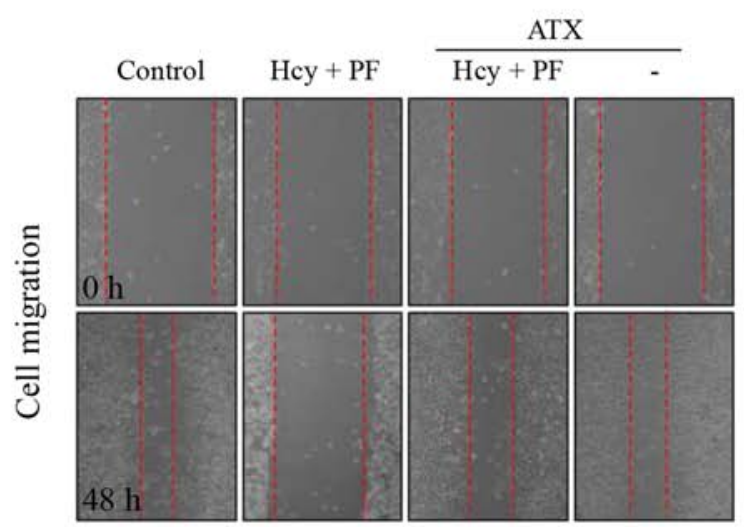

B

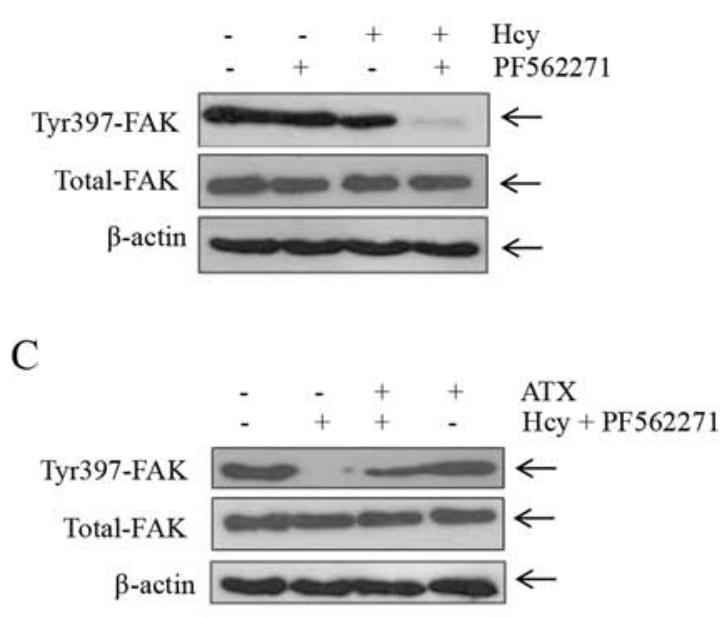

$\mathrm{E}$

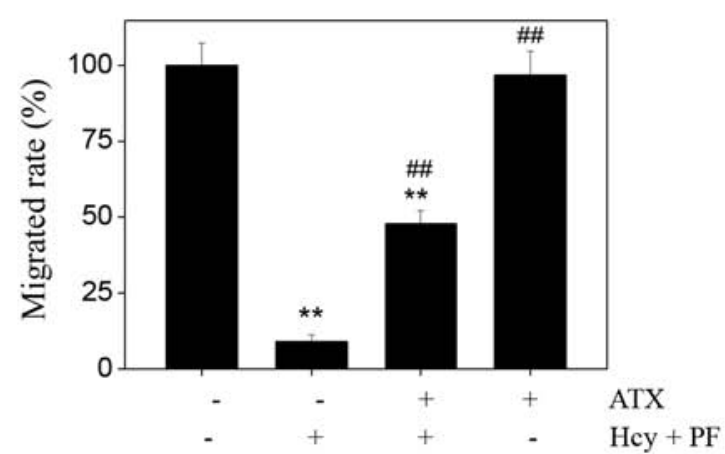

Figure 3. Hcy inhibits FAK phosphorylation. (A) Time-dependent effects of Hcy on VEGF-VEGFR2-FAK signaling. Human umbilical vascular endothelial cells were treated with $10 \mathrm{mM}$ Hcy for $72 \mathrm{~h}$. (B) PF562271 (FAK inhibitor) enhanced the suppressive effects of Hcy-induced dephosphorylation. Cells were treated with $10 \mathrm{nM}$ PF562271 and $10 \mathrm{mM} \mathrm{Hcy}$ for $72 \mathrm{~h}$. (C) ATX promoted FAK phosphorylation. Cells were pre-treated with $5 \mu \mathrm{M} \mathrm{ATX}$ for $6 \mathrm{~h}$, and co-treated with $10 \mathrm{nM}$ PF562271 and $10 \mathrm{mM}$ Hcy for $72 \mathrm{~h}$. Protein expression was examined by western blotting. (D) PF562271 enhanced the effects of Hcy on cell migration. (E) Statistical analysis of the rate of migration. All data and images were obtained from three independent experiments. ${ }^{* *} \mathrm{P}<0.01 \mathrm{vs}$. control; ${ }^{\# \#} \mathrm{P}<0.01 \mathrm{vs}$. Hcy-treated group ATX, astaxanthin; FAK, focal adhesion kinase; Hcy, homocysteine.

ROS production in a time-dependent manner, as demonstrated by the enhanced green fluorescence (Fig. 4A); however, ATX pre-treatment effectively inhibited Hcy-induced ROS production (Fig. 4B). In addition, ATX recovered the levels of Tyr397-FAK phosphorylation and improved HUVEC viability (Fig. 4C-E), which indicated similar protective effects to those of GSH, a ROS scavenger. The results suggested that Hcy induced ROS-dependent FAK phosphorylation; inhibition of ROS formation by ATX or GSH may increase FAK phosphorylation. Collectively, these results suggested that ATX could inhibit ROS-dependent FAK phosphorylation in Hcy-treated HUVECs.

\section{Discussion}

Numerous studies have supported the notion that hyperhomocysteinemia can induce endothelial cell apoptosis and promote the development of vascular diseases (10-17). This condition has therefore emerged as an independent risk factor for human CVD (34). The pathogenesis of hyperhomocysteinemia-associated human CVD is remains unclear, but may be due to dysregulated endothelial cell migration and invasion. Angiogenesis is a critical process required for physiological processes in the body, such as the regeneration of the damaged vascular tissues. The process of angiogenesis includes capillary or posterior venous endothelial cell activation, proliferation and migration. In addition, endothelial cell migration is one of the most important processes of angiogenesis. Endothelial cells can invade surrounding tissues, a prerequisite for the development of angiogenesis in response to migration signaling $(2,3)$. Hyperhomocystinemia may cause damage to vascular endothelial cells and consequently inhibit cell migration. The morphology of viable cells following Hcy treatment was notably altered than that of the control group, as determined by phase-contrast microscopy. These findings indicated that Hcy affected the normal function of endothelial cells. Atherosclerosis and cerebral hemorrhages are complex processes initiated at sites of endothelial cell injury. Injured endothelial cells can cause the endothelium-dependent relaxation of blood vessels, thereby resulting in the development of CVDs (35). In the present study, Hcy treatment significantly inhibited the migration and invasive potentials of HUVECs 
A
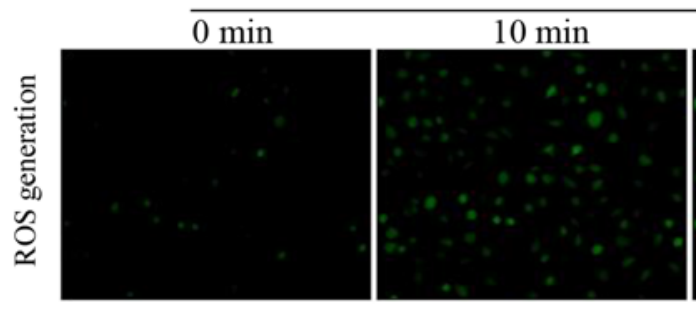

Hcy $(10 \mathrm{mM})$

B

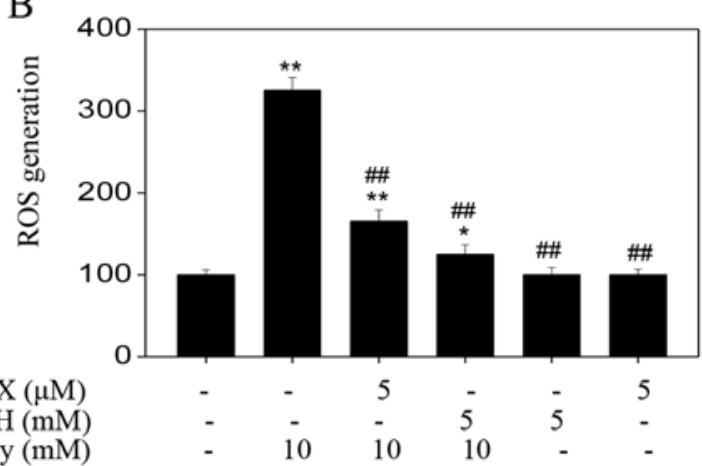

C

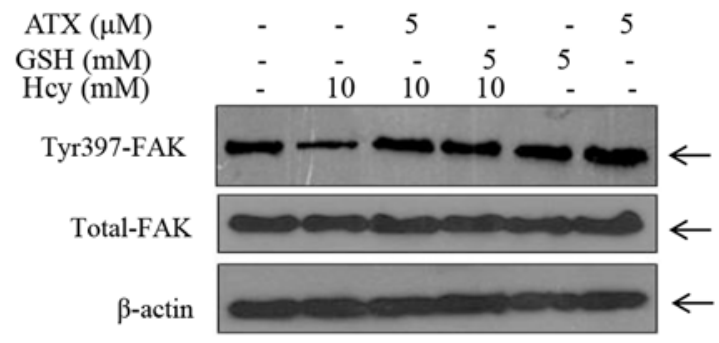

E

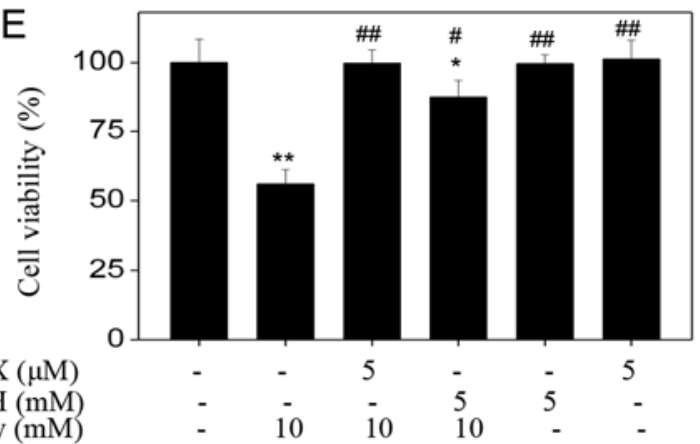

Figure 4. ATX inhibits ROS-dependent FAK phosphorylation. (A) Time-dependent ROS generation in Hcy-treated HUVECs. HUVECs were labeled with 2'7'-dichlorfluorescein diacetate for $20 \mathrm{~min}$, and cells were washed and treated with $10 \mathrm{mM}$ Hcy for various durations. ROS generation was analyzed with a fluorescence microscope (magnification, x200). (B) ROS generation was quantified by a microreader. (C) Effects of GSH or ATX pretreatment on Hcy-induced FAK phosphorylation. HUVECs were pre-treated with $5 \mathrm{mM} \mathrm{GSH}$ for $2 \mathrm{~h}$ prior to Hcy treatment. (D) Statistical analysis of p-FAK expression. (E) Effects of GSH or ATX pre-treatment on Hcy-induced HUVECs viability. All data and images were obtained from three independent experiments. ${ }^{*} \mathrm{P}<0.05,{ }^{* *} \mathrm{P}<0.01$ vs. control; ${ }^{\#} \mathrm{P}<0.05,{ }^{\#} \mathrm{P}<0.01$ vs. Hcy-treated group ATX, astaxanthin; FAK, focal adhesion kinase; Hcy, homocysteine; HUVECs, human umbilical vascular endothelial cells; $\mathrm{p}$, phosphorylated; ROS, reactive oxygen species.

compared with the control group. Thus, inhibiting endothelial cell migration and invasion may suppress the process of angiogenesis.

The formation of a mature vascular network is inhibited with vessel destabilization, followed by endothelial cell re-organization. This process is completed by vessel maturation (10-17). Angiogenesis requires the simultaneous precise regulation of a large number of angiogenic factors, including VEGF and VEGFR2, and their downstream signaling proteins, namely ERK, AKT and FAK (36). The VEGF-VEGFR2 axis aids endothelial cell recruitment and vascular permeability, whereas ERK activates endothelial cell proliferation; FAK promotes cell migration and invasion. VEGF and VEGFR2 have been considered to be the most important factors in this pathway, and serve key roles in regulating angiogenesis via the modulation of the degradation, differentiation, proliferation and migration of vascular endothelial cells (36-40). The VEGF-VEGFR axis eventually promotes the formation of new blood vessels (36-39). In clinical settings, patients with hyperhomocysteinemia usually possess endothelial cells with impaired endothelial activities, including cellular proliferation, migration and adhesion, which can harm human heart health (41-43). The present study revealed that Hcy induced endothelial cell dysfunction, and these effects were reversed by ATX pre-pretreatment, possibly via the regulation of FAK activation and increased cell migration in Hcy-treated HUVECs. Our findings provide insight into the potential therapeutic role of ATX in the prevention and chemotherapy of Hcy-mediated human CVDs.

\section{Acknowledgements}

Not applicable.

\section{Funding}

The present study was supported by the National Undergraduate Training Program for Innovation and Entrepreneurship (grant 
no. 201610439043 to FW Wang and grant no. 201510005001 to MH Zhang), the Sci-Tech Development Project of Taian in Shandong (grant no. 2016NS1058 to XY Fu) and The Japan Society for the Promotion of Science (JSPS) Postdoctoral Fellowship (grant no. P17751 to JK Ma).

\section{Availability of data and materials}

All data generated or analyzed during the present study are included in this published article.

\section{Authors' contributions}

JKM designed the experiments. XJW, DCT, FWW, XYF and CDF performed the experiments. MHW and XYF analyzed the data and prepared the images. JKM and XJW wrote the manuscript. All authors reviewed the manuscript.

\section{Ethics approval and consent to participate}

Not applicable.

\section{Patient consent for publication}

Not applicable.

\section{Competing interests}

The authors declare that they have no competing interests.

\section{References}

1. Fateeva VV and Vorobyova OV: Nitric oxide: From the mechanism of action to pharmacological effects in cerebrovascular diseases. Zh Nevrol Psikhiatr Im S S Korsakova 117: 131-135, 2017 (In Russian).

2. Poggesi A, Pasi M, Pescini F, Pantoni L and Inzitari D: Circulating biologic markers of endothelial dysfunction in cerebral small vessel disease: A review. J Cereb Blood Flow Metab 36: 72-94, 2016.

3. Holm H, Nägga K, Nilsson ED, Ricci F, Melander O, Hansson O, Bachus E, Magnusson M and Fedorowski A: Biomarkers of microvascular endothelial dysfunction predict incident dementia: A population-based prospective study. J Intern Med 282: 94-101, 2017.

4. Michinaga S and Koyama Y: Protection of the Blood-Brain barrier as a therapeutic strategy for brain damage. Biol Pharm Bull 40: 569-575, 2017.

5. Spencer JI, Bell JS and DeLuca GC: Vascular pathology in multiple sclerosis: Reframing pathogenesis around the blood-brain barrier. J Neurol Neurosurg Psychiatry 89: 42-52, 2018.

6. Nezu T, Hosomi N, Aoki S, Kubo S, Araki M, Mukai T, Takahashi T, Maruyama H, Higashi Y and Matsumoto M: Endothelial dysfunction is associated with the severity of cerebral small vessel disease. Hypertens Res 38: 291-297, 2015.

7. Dayal S, Baumbach GL, Arning E, Bottiglieri T, Faraci FM and Lentz SR: Deficiency of superoxide dismutase promotes cerebral vascular hypertrophy and vascular dysfunction in hyperhomocysteinemia. PLoS One 12: e0175732, 2017.

8. Hatefi M,Behzadi S, Dastjerdi MM, Ghahnavieh AA, Rahmani A, Mahdizadeh F,Hafezi Ahmadi MR and Asadollahi K: Correlation of homocysteine with cerebral hemodynamic abnormality, endothelial dysfunction markers, and cognition impairment in patients with traumatic brain injury. World Neurosurg 97: 70-79, 2017.

9. Škovierová H, Vidomanová E, Mahmood S, Sopková J, Drgová A, Cerveňová $\mathrm{T}$, Halašová $\mathrm{E}$ and Lehotský $\mathrm{J}$ : The molecular and cellular effect of homocysteine metabolism imbalance on human health. Int J Mol Sci 17: pii: E1733, 2016.
10. Catena C, Colussi G, Url-Michitsch M, Nait F and Sechi LA: Subclinical carotid artery disease and plasma homocysteine levels in patients with hypertension. J Am Soc Hypertens 9: 167-175, 2015.

11. Wang BR, Ou Z, Jiang T, Zhang YD, Zhao HD, Tian YY, Shi JQ and Zhou JS: Independent correlation of serum homocysteine with cerebral microbleeds in patients with acute ischemic stroke due to large-artery atherosclerosis. J Stroke Cerebrovasc Dis 25: 2746-2751, 2016

12. Wu GH, Kong FZ, Dong XF, Wu DF, Guo QZ, Shen AR, Cheng QZ and Luo WF: Association between hyperhomocysteinemia and stroke with atherosclerosis and small artery occlusion depends on homocysteine metabolism-related vitamin levels in Chinese patients with normal renal function. Metab Brain Dis 32: 859-865, 2017

13. Zhang Z, Wei C, Zhou Y, Yan T, Wang Z, Li W and Zhao L: Homocysteine induces apoptosis of human umbilical vein endothelial cells via mitochondrial dysfunction and endoplasmic reticulum stress. Oxid Med Cell Longev 2017: 5736506, 2017.

14. Yan TT, Li Q, Zhang XH, Wu WK, Sun J, Li L, Zhang Q and Tan HM: Homocysteine impaired endothelial function through compromised vascular endothelial growth factor/Akt/endothelial nitric oxide synthase signalling. Clin Exp Pharmacol Physiol 37: 1071-1077, 2010.

15. Pan L, Yu G, Huang J, Zheng X and Xu Y: Homocysteine inhibits angiogenesis through cytoskeleton remodeling. Biosci Rep 37: pii: BSR20170860, 2017.

16. Oosterbaan AM, Steegers EA and Ursem NT: The effects of homocysteine and folic acid on angiogenesis and VEGF expression during chicken vascular development. Microvasc Res 83: 98-104, 2012.

17. Zhang Q, Li Q, Chen Y, Huang X, Yang IH, Cao L, Wu WK and Tan HM: Homocysteine-impaired angiogenesis is associated with VEGF/VEGFR inhibition. Front Biosci (Elite Ed) 4: 2525-2535, 2012.

18. Chen $\mathrm{CH}$, Beard RS and Bearden SE: Homocysteine impairs endothelial wound healing by activating metabotropic glutamate receptor 5. Microcirculation 19: 285-295, 2012.

19. Rodriguez-Nieto S, Chavarria T, Martınez-Poveda B, Sánchez-Jiménez F, Rodríguez Quesada A and Medina MA: Anti-angiogenic effects of homocysteine on cultured endothelial cells. Biochem Biophys Res Commun 293: 497-500, 2002.

20. Fan CD, Sun JY, Fu XT, Hou YJ, Li Y, Yang MF, Fu XY and Sun BL: Astaxanthin attenuates homocysteine-induced cardiotoxicity in vitro and in vivo by inhibiting mitochondrial dysfunction and oxidative damage. Front Physiol 8: 1041, 2017.

21. Pang X, Si J, Xu S, Li Y and Liu J: Simvastatin inhibits homocysteine-induced CRP generation via interfering with the ROS-p38/ERK1/2 signal pathway in rat vascular smooth muscle cells. Vascul Pharmacol 88: 42-47, 2017.

22. Tian X, Zhao L, Song X, Yan Y, Liu N, Li T, Yan B and Liu B: HSP27 inhibits homocysteine-induced endothelial apoptosis by modulation of ROS production and mitochondrial Caspase-dependent apoptotic pathway. Biomed Res Int 2016: 4847874, 2016

23. Zhang M, Cui Z, Cui H, Wang Y and Zhong C: Astaxanthin protects astrocytes against trauma-induced apoptosis through inhibition of $\mathrm{NKCC1}$ expression via the $\mathrm{NF}-\kappa \mathrm{B}$ signaling pathway. BMC Neurosci 18: 42, 2017.

24. Nai Y, Liu H, Bi X, Gao H and Ren C: Protective effect of astaxanthin on acute cerebral infarction in rats. Hum Exp Toxicol 37: 929-936, 2018.

25. Zhang M, Cui Z, Cui H, Cao Y, Zhong C and Wang Y: Astaxanthin alleviates cerebral edema by modulating NKCC1 and AQP4 expression after traumatic brain injury in mice. BMC Neurosci 17: 60, 2016.

26. Lee DH, Lee YJ and Kwon KH: Neuroprotective effects of astaxanthin in oxygen-glucose deprivation in SH-SY5Y cells and global cerebral ischemia in rat. J Clin Biochem Nutr 47: 121-129, 2010.

27. Liu $X$ and Osawa T: Astaxanthin protects neuronal cells against oxidative damage and is a potent candidate for brain food. Forum Nutr 61: 129-135, 2009.

28. Lu YP, Liu SY, Sun H, Wu XM, Li JJ and Zhu L: Neuroprotective effect of astaxanthin on $\mathrm{H}(2) \mathrm{O}(2)$-induced neurotoxicity in vitro and on focal cerebral ischemia in vivo. Brain Res 1360: 40-48, 2010.

29. Shen H, Kuo CC, Chou J, Delvolve A, Jackson SN, Post J, Woods AS, Hoffer BJ, Wang Y and Harvey BK: Astaxanthin reduces ischemic brain injury in adult rats. FASEB $\mathrm{J} 23$ : 1958-1968, 2009. 
30. Wen X, Huang A, Hu J, Zhong Z, Liu Y, Li Z, Pan X and Liu Z: Neuroprotective effect of astaxanthin against glutamate-induced cytotoxicity in HT22 cells: Involvement of the Akt/GSK-3 $\beta$ pathway. Neuroscience 303: 558-568, 2015.

31. Wu Q, Zhang XS, Wang HD, Zhang X, Yu Q, Li W, Zhou ML and Wang XL: Astaxanthin activates nuclear factor erythroid-related factor 2 and the antioxidant responsive element (Nrf2-ARE) pathway in the brain after subarachnoid hemorrhage in rats and attenuates early brain injury. Mar Drugs 12: 6125-6141, 2014

32. Zhang XS, Zhang X, Wu Q, Li W, Wang CX, Xie GB, Zhou XM Shi JX and Zhou ML: Astaxanthin offers neuroprotection and reduces neuroinflammation in experimental subarachnoid hemorrhage. J Surg Res 192: 206-213, 2014.

33. Zhang XS, Zhang X, Wu Q, Li W, Zhang QR, Wang CX, Zhou XM, Li H, Shi JX and Zhou ML: Astaxanthin alleviates early brain injury following subarachnoid hemorrhage in rats: Possible involvement of Akt/bad signaling. Mar Drugs 12: 4291-4310, 2014.

34. Zhang XS, Zhang X, Zhou ML, Zhou XM, Li N, Li W, Cong ZX, Sun Q, Zhuang Z, Wang CX and Shi JX: Amelioration of oxidative stress and protection against early brain injury by astaxanthin after experimental subarachnoid hemorrhage. J Neurosurg 121: 42-54, 2014.

35. Bi YL, Mi PY, Zhao SJ, Pan HM, Li HJ, Liu F, Shao LR, Zhang HF, Zhang P and Jiang SL: Salinomycin exhibits anti-angiogenic activity against human glioma in vitro and in vivo by suppressing the VEGF-VEGFR2-AKT/FAK signaling axis. Int J Mol Med 39: 1255-1261, 2017.

36. Lai WK and Kan MY: Homocysteine-induced endothelial dysfunction. Ann Nutr Metab 67: 1-12, 2015.

37. Tiwari A, Pattanaik N, Mohanty Jaiswal A and Dixit M: Increased FRG1 expression reduces in vitro cell migration, invasion and angiogenesis, ex vivo supported by reduced expression in tumors. Biosci Rep 37: pii: BSR20171062, 2017.
38. Bai Y, Bai L, Zhou J, Chen $\mathrm{H}$ and Zhang L: Sequential delivery of VEGF, FGF-2 and PDGF from the polymeric system enhance HUVECs angiogenesis in vitro and CAM angiogenesis. Cell Immunol 323: 19-32, 2018.

39. Heldin J, O'Callaghan P, Hernández Vera R, Fuchs PF, Gerwins $P$ and Kreuger J: FGD5 sustains vascular endothelial growth factor A (VEGFA) signaling through inhibition of proteasome-mediated VEGF receptor 2 degradation. Cell Signal 40: 125-132, 2017.

40. Lv J, Sun B, Mai Z, Jiang M and Du J: STAT3 potentiates the ability of airway smooth muscle cells to promote angiogenesis by regulating VEGF signalling. Exp Physiol 102: 598-606, 2017.

41. Mahecha AM and Wang H: The influence of vascular endothelial growth factor-A and matrix metalloproteinase-2 and-9 in angiogenesis, metastasis, and prognosis of endometrial cancer. Onco Targets Ther 10: 4617-4624, 2017.

42. Tang F, Pacheco MTF, Chen P, Liang D and Li W: Secretogranin III promotes angiogenesis through MEK/ERK signaling pathway. Biochem Biophys Res Commun 495: 781-786, 2018.

43. Abdelzaher LA, Imaizumi T, Suzuki T, Tomita K, Takashina M and Hattori Y: Astaxanthin alleviates oxidative stress insults-related derangements in human vascular endothelial cells exposed to glucose fluctuations. Life Sci 150: 24-31, 2016.

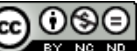

This work is licensed under a Creative Commons Attribution-NonCommercial-NoDerivatives 4.0 International (CC BY-NC-ND 4.0) License. 